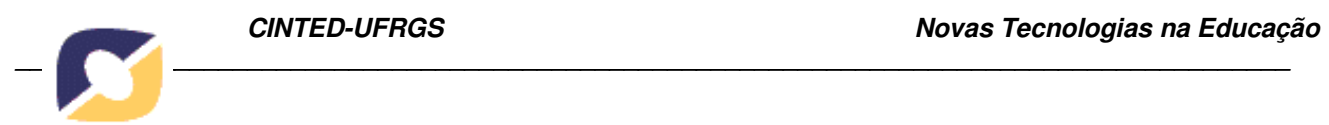

\title{
Aplicação de Jogos e Simuladores como Instrumentos para Educação e Segurança no Trânsito
}

\author{
Amanda B. Balbinot , Maria Isabel Timm ${ }^{1}$, Milton Antônio Zaro \\ ${ }^{1}$ Programa de pós-graduação de Informática na Educação - Universidade Federal do Rio \\ Grande do Sul (UFRGS) - Porto Alegre - RS - Brazil \\ ambalbinot@gmail.com, beta@cesup.ufrgs.br, zaro@ibtec.org.br
}

Resumo. Este artigo tem por objetivo apresentar jogos, simuladores e pesquisas desenvolvidas e aplicadas à educação e segurança de trânsito. O tema merece atenção, pois os acidentes de trânsito encontram-se presentes no dia a dia das cidades, pondo em risco a segurança de pessoas. Pretende-se evidenciar ações educativas e como as Tecnologias da Informação e Comunicação contribuem propiciando múltiplos estímulos cognitivos, no desenvolvimento de ambientes que favoreçam a avaliação de comportamentos, bem como, a construção de conhecimento. Realizando-se assim, uma reflexão sobre as possibilidades e aplicações destes recursos.

Palavras-chave: Jogos e Simuladores, Educação para o Trânsito, Segurança no Trânsito.

\section{Application of games and simulations as tools for education and safety in traffic}

\begin{abstract}
This article aims to provide games, simulations and research developed and applied to education and traffic safety. The subject deserves attention, because traffic accidents are present in the daily life of cities, endangering the safety of people. It is intended to highlight acts of education and ways in which Information and Communication Technologies contribute for multiple cognitive stimuli in the development of environments that support the assessment of behavior, as well as the construction of knowledge. It is concluded that this paper makes a reflection on the possibilities and applications of these resources.
\end{abstract}

Keywords: Games and Simulators, Education for Transit, Transit Security.

\section{Introdução}

No Brasil, os acidentes de trânsito geram custos sociais, ambientais, psicológicos e financeiros (IPEA, 2006). Neste cenário a falha humana é considerada a principal causa de acidentes, que compreende atitudes como: dirigir em alta velocidade, fazer rachas, avançar sinal vermelho e imprudências. Em todo o mundo, os acidentes vitimam mais de um milhão de pessoas por ano, e deixando entre 20 milhões e 50 milhões de pessoas feridas. (Ministério da Saúde, 2007). Investir na formação de condutores e pedestres parece ser uma medida importante, para a redução deste problema.

A aprendizagem veicular exige do aprendiz a manifestação de capacidades e a aquisição de habilidades motoras, sensoriais, cognitivas e de informações sobre o trânsito, 


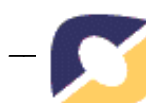

com suas implicações técnicas, preventivas, defensivas e punitivas. As funções cognitivas, quando relacionadas à direção veicular, incluem "memória, atenção, avaliação sistemática do ambiente e outras habilidades visuoespaciais, verbais e de processamento de informações, tomada de decisões e resolução de problemas. Estas funções devem se processar de modo dinâmico" (PIRITO, 1999, p. 27). Percebe-se assim, que o trânsito configura-se em um ambiente complexo, e conduzir não é uma atividade tão simples como se imagina.

No entanto, nos deparamos muitas vezes com a falta de uma cultura educacional que relacione as deficiências dos condutores e pedestres com as necessidades da educação para o trânsito. Desta forma, avaliar as estratégias e pesquisas desenvolvidas e aplicadas na área de educação e segurança no trânsito é relevante, na reflexão sobre o tema. A aplicação de jogos e simuladores nesta área possibilita o desenvolvimento dos processos de tomada de decisão e de avaliação de atitudes no trânsito, por meio de um ambiente virtual.

\section{A Aplicabilidade de Jogos e Simuladores}

No trânsito encontra-se uma gama de variáveis, constantemente, interagindo como pedestres, carros, motocicletas, bicicletas e animais. Desta forma, os ambientes virtuais favorecem a construção de cenários e simulações as quais permitem ao jogador a interação com o ambiente.

A utilização de computadores e recursos multimídia na aprendizagem pode favorecer o surgimento de idéias, emoções, atitudes e habilidades, as quais propiciam uma relação cognitiva e interativa dos estudantes com o objeto de conhecimento (VALENTE, 1993). Segundo Ribeiro (2006), o desenvolvimento de um cenário virtual, através do jogo, traz benefícios, como recriar cenários de difícil acesso (temporários e perigosos), criar um espaço virtual com a ocorrência de problemas e situações contextualizadas. Para a educação para o trânsito, a possibilidade de criar ambientes com esses recursos favorece a aprendizagem, a interação sujeito-ambiente, como, por exemplo, simular situações perigosas e, então, verificar a reação do sujeito - isso em um ambiente controlado e sem riscos.

Muitas pesquisas desenvolvidas utilizam simuladores para testar comportamentos (BACKLUND et al., 2008; FREUND e COLGROVE, 2008; ELLIOTT et al., 2007; STRADLING e MEADOWS, 2000). Os simuladores de condução propiciam grandes vantagens, permitem aos investigadores obter medidas confiáveis do comportamento de velocidade (são gravados dados de momento a momento ao longo de um percurso) e um controle mais rigoroso das condições experimentais, em que todos os motoristas estão expostos aos mesmos estímulos (Elliott et al., 2007).

Segundo Backlund et al. (2008) os jogos não são realistas, em todos os sentidos de condução, mas parecem ter um impacto sobre alguns aspectos da condução de um automóvel. Alguns simuladores de alta fidelidade permitem ao condutor a nítida sensação de estar em um veículo real, o sistema interativo responde as ações do jogador de acionar o freio, o acelerador e a direção. A Figura 1 apresenta um modelo destes simuladores de alta fidelidade (Drews et al., 2008; Freund e Colgrove, 2008; Elliott et al., 2007). 


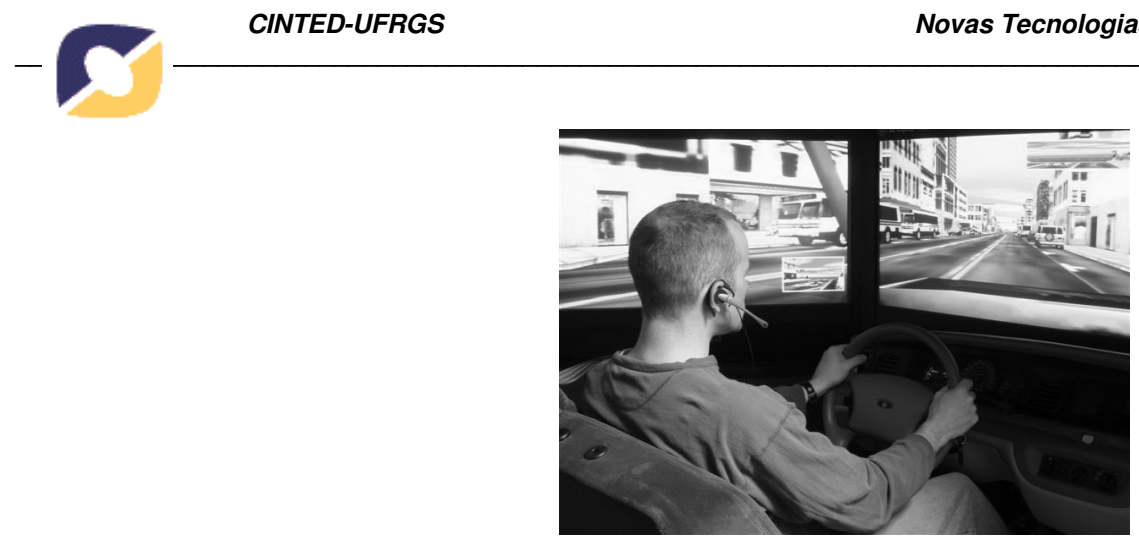

Figura 1 - Participante durante condução no simulador (Drews et al., 2008).

Os simuladores de direção produzem ambientes virtuais e possibilitam um controle muito mais rigoroso das condições experimentais (Bayarri, Fernández \& Sanmartin, 1996). Assim, sua utilização vem sendo difundida na investigação sobre o comportamento de condutores, em condições como fadiga, sono, neblina, chuva dentre outras variáveis. Mas, os custos deste tipo de equipamento são elevados, limitando sua utilização.

\subsection{Jogos digitais}

Existe um crescente interesse na utilização de jogos de computador, os quais podem ser utilizados com diversas finalidades e estratégias. Conforme Greenfield (1988), os jogos de ação desenvolvem capacidades, como: habilidades viso-motoras e espaciais, esforço indutivo - as jogadas iniciais que ocorrem por acaso são substituídas por jogadas intencionais e sequenciais através de indução -, a coordenação da informação visual proveniente de múltiplas perspectivas, etc.

Backlund et al. (2008) distinguem os jogos de diversão dos que denominam como jogos sérios, que possuem um objetivo definido, e não de mera diversão. Com relação aos jogos de condução, os autores afirmam que estes permitem verificar algumas ações dos jogadores ao dirigir, como em situações que exijam movimentação e decisões rápidas, análise do uso de sinais, da velocidade, a utilização de espelhos retrovisores, alterações de faixas e conversões.

Os jogos digitais, que apresentam veículos como temas centrais, em sua grande maioria primam pelo entretenimento e diversão, enfatizando a velocidade - a pontuação maior é dos mais velozes e habilidosos. Um exemplo seria o Need For Speed (jogo de corrida com competições de rua) (ver Figura 2). O último lançamento desse jogo produz excepcional realidade virtual de uma cidade, com perseguições, rachas, acidentes. E quanto maior a velocidade e a agilidade do jogador, ele pode ter seu nome no hall da fama do jogo, não havendo qualquer preocupação com as regras de trânsito para atingir seu objetivo.

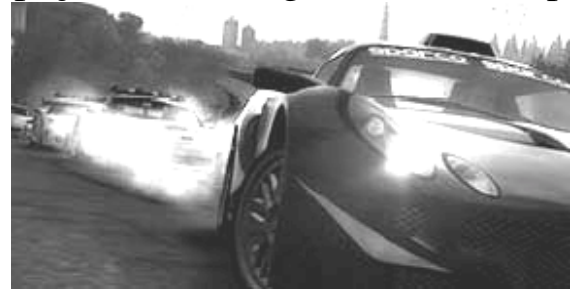

Figura 2 - Competição na rua (Fonte: EA games Need for speed, 2007) 
Esses tipos de jogos, mesmo que ofereçam recursos importantes, como uma realidade virtual detalhada, exigem habilidade e reações rápidas de condução. Seus objetivos, no entanto, não favorecem a segurança no trânsito - aspecto fundamental na formação de novos condutores e para condutores não iniciantes. Conforme descrevem pesquisadores da Universidade Ludwig-Maximilians e do Allianz Center for Technology, os jogos de corrida em que o mérito se encontra tanto em violar regras de trânsito como em conduzir em alta velocidade, após sua utilização, desenvolvem nos participantes um número significativamente maior de acessibilidade a pensamentos e sentimentos ligados à tomada de risco do que aqueles que desempenharam um jogo neutro. Isso sugere que os jogos de corrida levam a uma condução arriscada, incitando pensamentos e sentimentos que podem resultar em comportamentos de risco à direção (Fischer et al., 2007).

Quanto às implicações possíveis dos jogos de corrida, existe a preocupação com as crianças, caso iniciem a jogá-los em média aos 10 anos, pois pode vir a fixar atitudes de riscos que levam à condução insegura. Essas crianças, quando crescerem, possivelmente as executarão atrás do volante (Jörg Kubitzki, apud Ficher et al., 2007). Autores observam que as pesquisa nessa área ainda são incipientes, apresentam resultados ambíguos, indicando a necessidade de mais estudos. Em grande parte, o debate sobre os efeitos negativos dos jogos violentos em computador é semelhante ao debate sobre a violência em filmes e desenhos (BACKLUND, 2008).

Sendo assim, criar modelos de jogos que propiciem às crianças, aos jovens e adultos outras formas de envolvimento com veículos é importante, o que se potencializa se oferecer, ainda, aspectos não só de entretenimento, mas questões relevantes a respeito de trânsito e segurança. Atualmente, vem crescendo o investimento nessa área, não pretendendo, entretanto, concorrer com os jogos de corrida, mas oferecer outras possibilidades de abordagem. São exemplos os jogos disponibilizados em sites dos DETRANs do país e da EPTC, que apresentam atividades como jogos de memória, de habilidades e conhecimentos sobre legislação de trânsito.

O DETRAN/SC disponibiliza o jogo "Carrinho", que testa a habilidade e a coordenação do jogador ao desviar de obstáculos na pista (evitar estragos) em um percurso, com tempo delimitado (ver imagem da Figura 3). Esse jogo possui fácil utilização dos comandos, o que favorece o jogador na atividade.

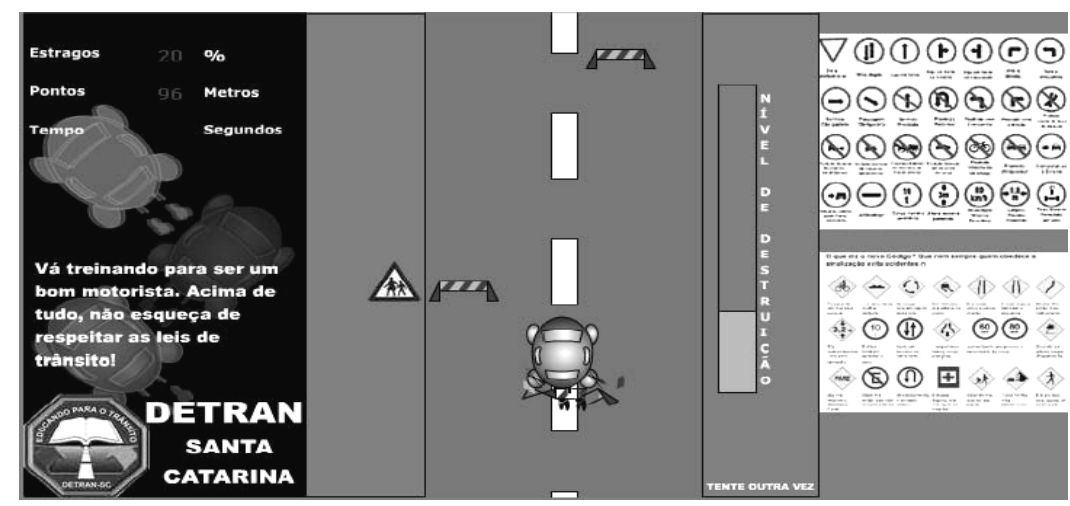

Figura 3 - Percurso com obstáculos (DETRAN/SC) 
O jogo - Teste Situações é um teste destinado ao desempenho do jogador, em uma viagem de férias. São avaliadas as escolhas do jogador frente a situações e riscos que surgem no trajeto, testando habilidades, atenção e conhecimentos de procedimentos de segurança no trânsito, conforme exemplo ilustrado na Figura 4. A imagem (a) apresenta uma pergunta com alternativas de resposta, após a escolha, surge à imagem (b) com o resultado da opção escolhida, que neste caso foi considerada correta, apresentando o Sinal Verde e uma explicação (DETRAN-CE).
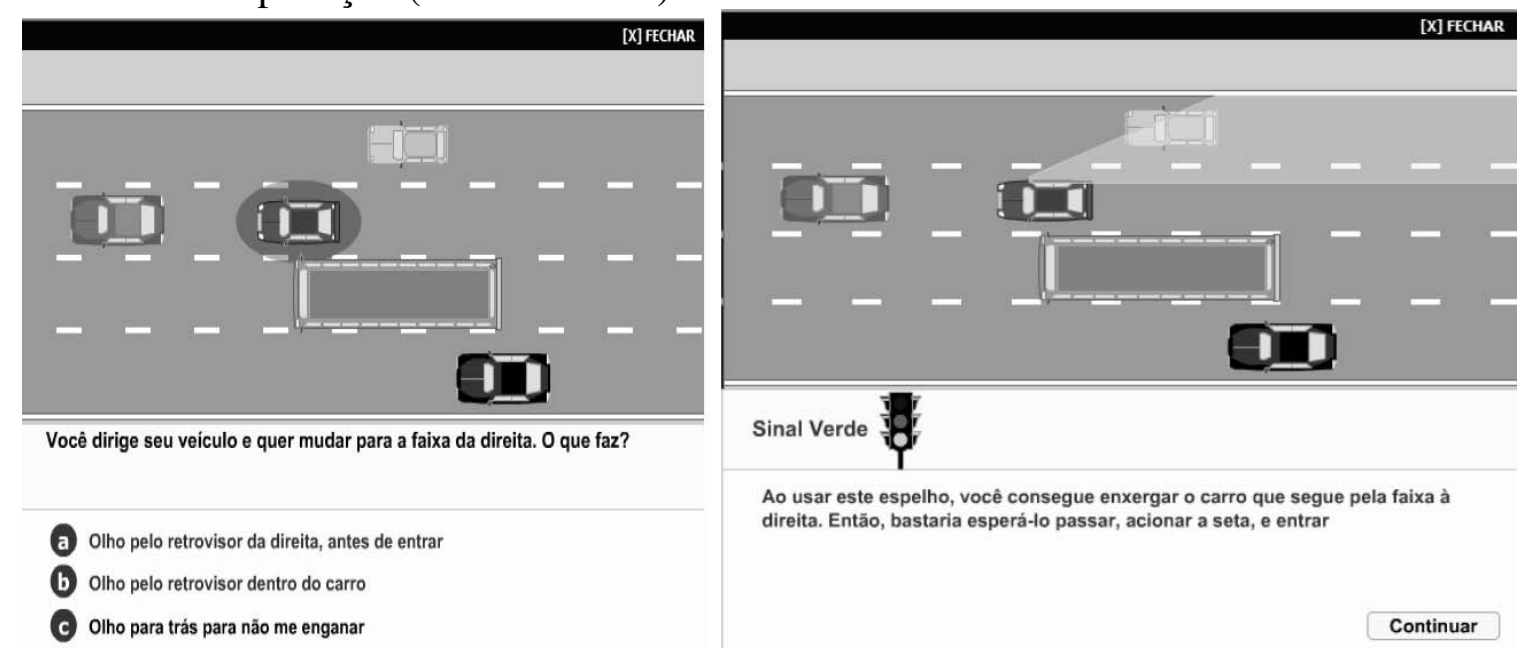

Figura 4 - (a) Pergunta do Teste Situações. (b) Avaliação da resposta (DETRAN-CE)

O Software Educacional "Sou Dez no Trânsito" foi desenvolvido para crianças dos anos iniciais. Conforme Gessi (2003), criador desse ambiente, o jogo é composto por elementos do trânsito, como placas, faixa de pedestres, pedestres, veículos e também elementos que compõem uma cidade, tais como escola, hospital, praças, fazenda, etc. Ele é interativo e trabalha com um padrão de botões de ação, além de utilizar recursos de som, imagem, texto e animações. Na modelagem do protótipo, foi utilizado FLASH, AUTOCAD e ARQ_3D. Os conteúdos são apresentados de forma dividida para crianças dos anos iniciais $\left(1 .^{\circ}, 2 .^{\circ}, 3 .^{\circ}\right.$ e $\left.4 .^{\circ}\right)$, e essa divisão encontra-se por módulos, apresentados em um ônibus escolar e representados por crianças à janela do veículo.

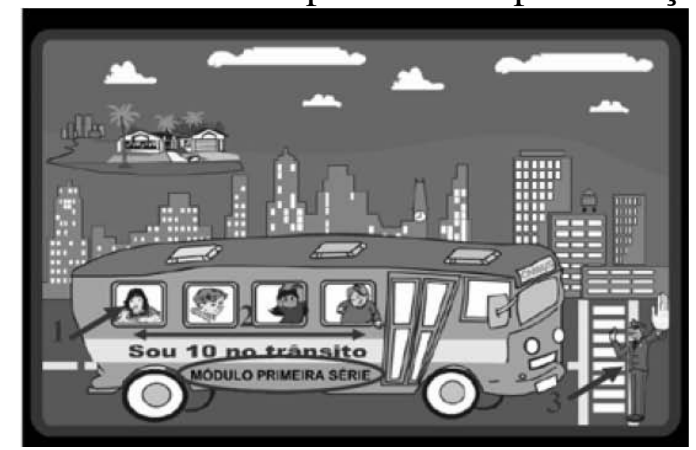

Figura 6 - Menu seleção módulos (Gessi, 2003).

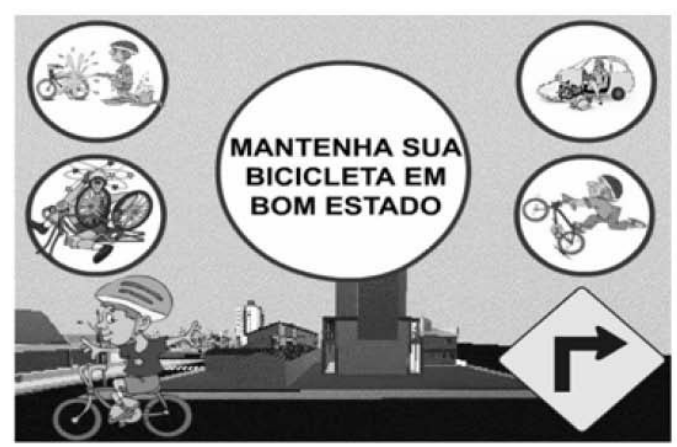

Figura 7 - Dicas segurança ciclistas (Gessi, 2003).

Conforme Gessi (2003) a construção do software educacional de trânsito, requer à participação de uma equipe multidisciplinar, por ser necessário conhecer o desenvolvimento cognitivo das crianças, delimitar os assuntos abordados em detrimento 


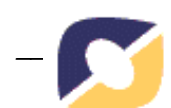

das fases de desenvolvimento das crianças, as estratégias que serão utilizadas no desenvolvimento de interfaces e na utilização de recursos multimídia para propiciar uma aprendizagem, através da interação com o objeto do conhecimento. Destinado assim, atividades pertinentes à faixa etária dos jogadores.

O jogo EducaTrans é um jogo educativo mais complexo, desenvolvido para o aprendizado no Trânsito em que o aprendiz poderá navegar em um ambiente que reproduz um cenário real com regras de trânsito bem definidas. O público-alvo, a que se destina, compreende alunos do Ensino Fundamental I e II e Ensino Médio. O jogo consiste em uma simulação do fluxo de pedestres, motoristas e ciclistas que partem de um mesmo ponto e buscam atingir o mesmo destino no menor tempo e com o menor risco à sobrevivência. $\mathrm{O}$ jogador pode escolher qual papel pretende desenvolvendo no jogo como pedestre, ciclista e motorista. Com papeis diferentes no trânsito, o jogador deverá estar atento às leis de trânsito, que deverá respeitar durante o jogo, para ter um bom desempenho. A Figura 5 apresenta imagens do jogo EducaTrans (Assis, 2006).
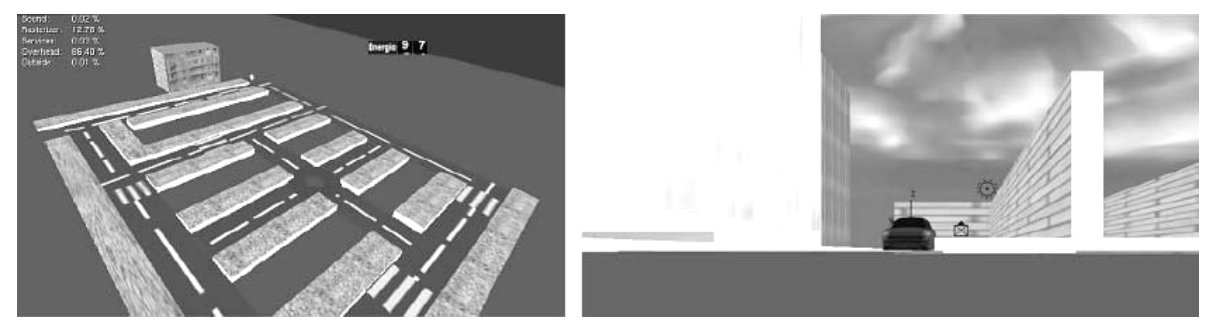

Figura 5 - (a) Vista superior do EducaTrans. (b) Veículo no cenário do jogo (Assis, 2006).

Percebe-se, assim, que esse tipo de ambiente possibilita a observação e a classificação das atitudes tomadas frente a situações específicas, tornando-se uma ferramenta útil para a avaliação de comportamentos. Os jogos pretendem, de forma lúdica, apresentar conceitos, despertar a curiosidade, a interação e habilidades do jogador frente a situações de trânsito. Alguns se apresentam de forma mais simples, outros mais complexos, em seus recursos tecnológicos, mas todos, de alguma forma, trazem contribuições à área de trânsito.

\subsection{Simuladores}

Alguns simuladores de alta fidelidade permitem aos condutores a nítida sensação de estarem em um veículo real. Assim, sua utilização vem sendo difundida na investigação de comportamento de condutores em condições como fadiga, sono e utilização de celular. Mas os custos desse tipo de equipamento são elevados, o que limita o acesso e a sua utilização.

Em São Paulo, algumas empresas contam, para a realização da Semana Interna de Prevenção de Acidentes de Trabalho (SIPAT), com o Simulador de trânsito e direção defensiva, desenvolvido nos rígidos padrões estadunidenses e aprovado pela legislação do Departamento de Veículos a Motor da Califórnia. Esse simulador apresenta situações reais de trânsito, em simulação com carro, com painel configurado para avaliar o desempenho do 


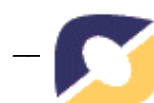

motorista, o movimento dos olhos e da cabeça, o estado de alerta com carga progressiva de trabalho e o tempo de reação de motoristas ${ }^{1}$. .
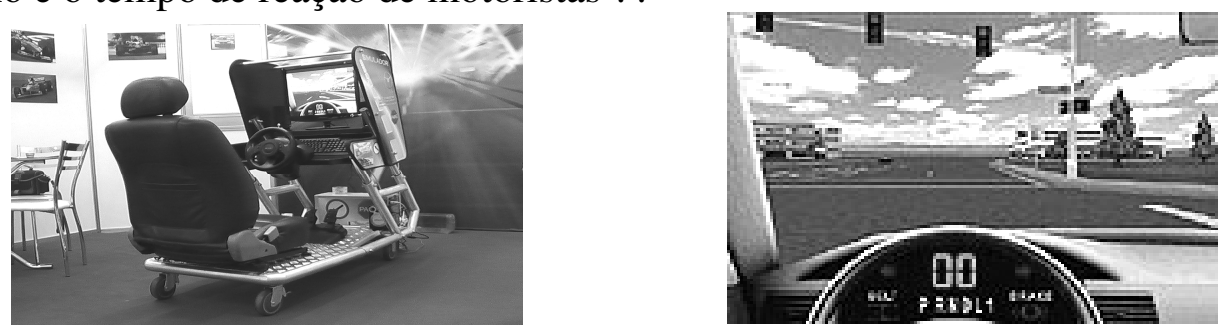

Figura 8 - Imagens do simulador de trânsito e direção defensiva (Simulador de trânsito).

A Universidade de Leeds conta com o simulador de condução, o Jaguar S-type vehicle, para o desenvolvimento de pesquisas sobre o comportamento de condutores como frente a controladores de velocidade, respostas psicofisiológicas, efeitos de neblina, dificuldades frente ao baixo atrito na pista, dentre outros projetos. Este é um exemplo de simulador de alta fidelidade, na cabine encontram-se todas as funções inerentes a um painel e instrumentação de um veículo e o motorista pode sentir a carga de todos os controles normais, incluindo o volante e os pedais.
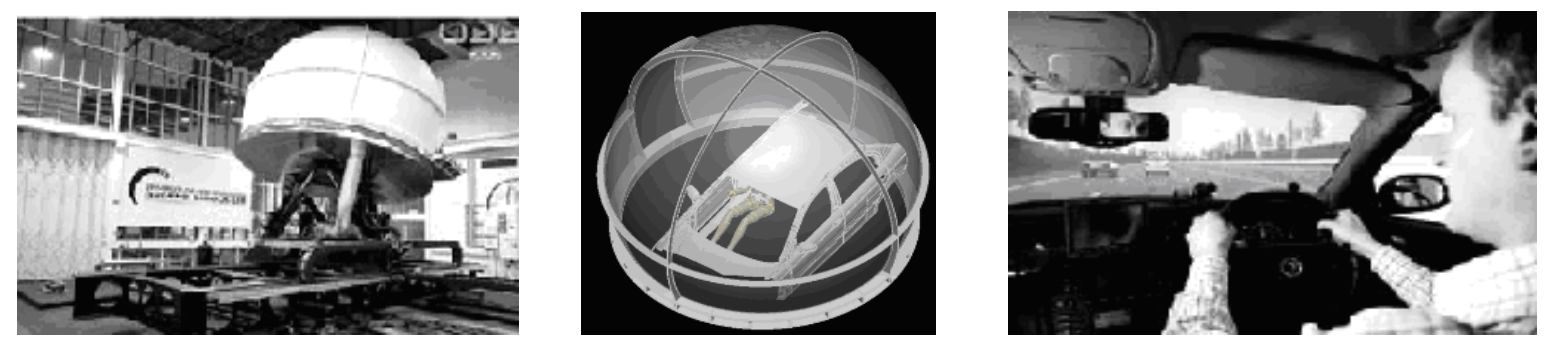

Figura 9 - (a) imagem externa do simulador, (b) e (c) imagens internas do simulador (University of Leeds- Driving Simulator, 2008).

Um exemplo de simulador capacitado a reproduzir a aleatoriedade do sistema real através de distribuições probabilísticas, encontra-se no Synchro / Simtraffic, sendo a empresa Tectran, uma das primeiras a utilizá-lo no desenvolvimento de modelos para diferentes ambientes em empresas como: FIAT, Mannesmann, Vale do Rio Doce, em Rodoviários: Nova Dutra, Fernão Dias. Macro-simulação é o estudo do comportamento agregado do tráfego e a micro-simulação estuda o comportamento individual dos motoristas. A Figura 10 apresenta imagens de simulações do SimTraffic.
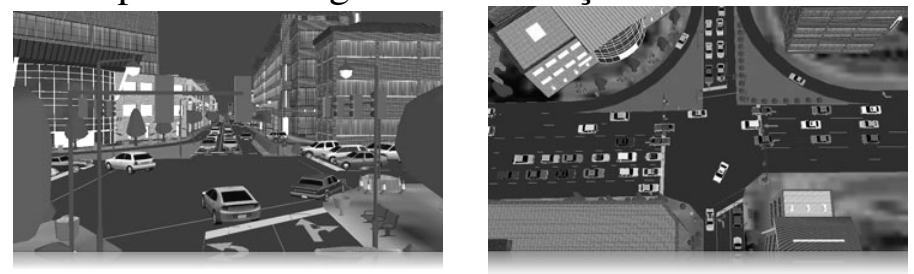

Figura 10 - Imagens do SimTraffic. Fonte: site Tectran.

\footnotetext{
${ }^{1}$ http://www.defensiva.com.br/SIMULADOR.htm
} 


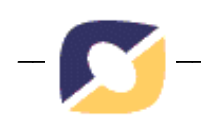

Este modelo de simulação pode apresentar 10 tipos de motoristas, dos mais cuidadosos - Tipo 1 aos mais agressivos - Tipo 10, alocados aleatoriamente, na direção dos veículos durante as simulações. Diferentes comportamentos destes motoristas que se expressam nos tempos de reação, nas atitudes no tráfego, criam cenários mais próximos da realidade e permite resultados mais consistentes nas análises.

Com relação a experimentos envolvendo as condições climáticas, o tempo influenciando a condução, pesquisadores como Snowden et al. (1998) constataram em um ambiente virtual com simulador de direção que, a neblina muda à percepção de velocidade e esta mudança de contraste proporcionada pela incidência de neblina é interpretada pelo cérebro como mudança de velocidade. Embora os condutores tenham consciência que deveriam reduzir a velocidade em situação de neblina devido à redução de visibilidade, eles trafegavam demasiado rápido. Isto se deve ao fato de que eles pensam estar trafegando a uma velocidade menor do que realmente estão. Os sujeitos deste experimento deveriam dirigir a certa velocidade, no entanto a aumentavam à medida que o cenário se tornava mais nebuloso. São estes comportamentos, que podem ser avaliados em um ambiente seguro e controlado, permitindo verificar certos comportamentos de condutores frente a ambientes adversos e elaborar formas de prevenção e segurança no trânsito.

Campagne et al. (2004), apresentam um outro experimento em simulador de condução constatou que ao dirigir por muito tempo monotonamente e à noite, a maioria dos motoristas mostra progressivamente sinais de fadiga visual e perda da atenção sustentada. Foram estudados 46 motoristas, a atividade proposta era percorrer uma via de 350 quilômetros à noite. Os erros foram medidos em termos do número de incidentes e de desvios de velocidade alta. A evolução do nível de vigilância fisiológica foi avaliada por meio do eletroencefalograma. Esse experimento, por meio de um percurso monitorado, mede os incidentes cometidos, como desvio e alta velocidade, correlacionando-os a um comprometimento da atenção sustentada pela fadiga, apresentando considerações sobre condutas de risco cometidas, a que os motoristas devem estar atentos para evitar acidentes.

A viabilidade do simulador como uma ferramenta de aprendizagem também, vem sendo avaliada experimentalmente e pode ser uma ferramenta utilizada para melhorar a aprendizagem de condutores (Backulund et al., 2008). No estudo desenvolvido pelos autores, os participantes, após conduzirem em um simulador, responderam a um questionário sobre suas experiências durante o experimento, com questões como: "eu violava muito as regras de trânsito", com alternativas desde totalmente de acordo até totalmente em desacordo. Esse procedimento pretendia levar a uma reflexão sobre o que foi executado. Outra estratégia apresentada, como forma de favorecer e reconhecer a aprendizagem, é a gravação de situações, as quais permitem aos instrutores apresentarem e transmitir a gravidade de certas situações.

O levantamento realizado de jogos e simuladores de condução apresenta a diversidade de objetivos que podem ser traçados a partir dessas ferramentas e as possibilidades de propiciar informação, testar conhecimentos, habilidades, mensurar (variáveis), desenvolver possibilidades de construção de conhecimento, dentre outras. A complexidade e tecnologia utilizadas são diferentes em alguns casos. No entanto, todos 


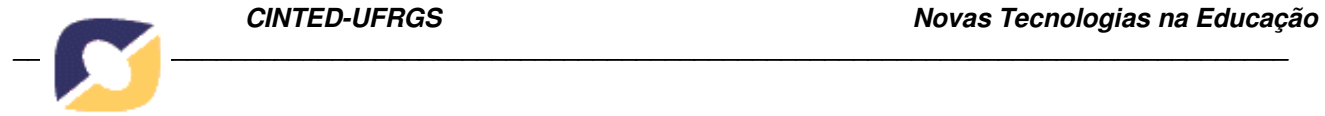

possuem sua funcionalidade e utilidade, as quais podem e devem ser utilizadas na área de trânsito

\section{Conclusões}

As questões sobre trânsito, principalmente no que se referem aos elevados índices de acidentes merecem atenção e estudos científicos. A chave de um progresso educacional significativo pode estar na análise das deficiências dos motoristas e no desenvolvimento de condutores mais conscientes e informados.

As crianças como futuros condutores ao conhecerem questões sobre o trânsito podem, gradativamente conscientizarem-se de sua responsabilidade no trânsito. Muitas vezes, os pequenos aprendizes tornam-se fiscais dos erros cometidos no trânsito.

Comportamentos arraigados de desrespeito às normas de trânsito exigem estratégias educacionais, de fiscalização e punições. No entanto, possibilitar por meio de jogos e simuladores que o jogador se confronte com seu comportamento, pode ser uma estratégia significativa. Em alguns casos, propiciar um feed-back ao usuário a respeito de seu desempenho pode servir para a tomada de consciência de sua conduta no trânsito. Assim, por meio de um ambiente controlado, se possa identificação as variáveis que interferem no desempenho de condutores e pedestres, contribuindo para a formulação de ações preventivas.

\section{Agradecimentos}

Ao apoio do CNPQ.

\section{Referências bibliográficas}

ASSIS, Gilda A; FICHEMAN, I \& Outros. EducaTrans: um Jogo Educativo para o Aprendizado do Trânsito. RENOTE - Revista Novas Tecnologias na Educação, CINTED/UFRGS, Porto Alegre - RS, V.4 N 2. 2006.

BACKLUND, Per; ENGSTRÖM, H.; JOHANNESSON, M.; LEBRAM, M. Games for traffic education: An experimental study of a game-based driving simulator. Simulation \& Gaming, May, 19, 2008.

BAYARRI, S., FERNÁNDEZ, M; SANMARTIN, J. (1996). Scenario modelling tools for driving simulation experiments. In: International Conference on Traffic and Transport Psychology. Anais. Valencia, España. Maio, p. 22-25, 1996.

CAMPAGNE, A., PEBAYLE, T. \& MUZET, A. Correlation between driving errors and vigilance level: influence of the driver's age. Physiological Behaviors, 80(4), p. 515 524, 2004.

DETRAN-CE. Departamento Estadual de Trânsito do Ceará. Teste Situações. Disponível:http://www.detran.ce.gov.br/site/includes/_janela.asp?url=../janelas/jogoSit uacoes.ht ml. Acesso em: 20 Março 2008.

DETRAN/SC. Departamento Estadual de Trânsito de Santa Catarina. Apresenta o Jogo do carrinho. Disponível: http://www.detran.sc.gov.br/educacao/carrinho.htm. Acesso em: 20 março 2008.

EA games Need for speed. Apresenta Need for speed prostreet. Disponível: 
http://www.ea.com/prostreet. Acesso 20 Dezembro 2007.

ELLIOTT, Mark A.; Armitage, Christopher; Baughan Christopher J. Using the theory of planned behaviour to predict observed driving behaviour British Journal of Social Psychology, 46, 2007, p.69-90.

FISCHER, Peter; KUBITZKI, Jörg; GUTER, Stephanie; FREY, Dieter . Virtual driving and risk taking: Do racing games increase risk-taking cognitions, affect, and behaviors? Journal of Experimental Psychology: Applied. Vol 13(1), Mar 2007, P. 22-31.

FREUND, Barbara; COLGROVE, Leigh Anna A. (2008). Error specific restrictions for older drivers: Promoting continued independence and public safety. Accident Analysis and Prevention, v. 40, pp. 97-103.

GESSI, N. Luis. O uso da informática e de recursos multimídia para o desenvolvimento de uma ferramenta didática para a educação no trânsito nos anos iniciais. Monografia do curso de especialização em informática na educação. Universidade Regional Integrada do Alto Uruguai e das Missões, Santo Ângelo, 2003.

GREENFIELD, Patrícia Marks. O desenvolvimento do raciocínio na era da eletrônica : os efeitos da tv, computadores e videogames. Tradução de Cecília Bonamine. São Paulo; :Summus, 1988. Cap 7 : Videogames : p. 85-106.

IPEA. Impactos sociais e econômicos dos acidentes de trânsito nas rodovias brasileiras Relatório Final. Brasília: IPEA/DENATRAN/ANTP, 2006. Disponível: http://www.ipea.gov.br/default.jsp. Acesso em: 20 março 2007.

Ministério da Saúde. Mortes no trânsito aumentam 9\% em três anos. Disponível: http://portal.saude.gov.br/portal/aplicacoes/noticias/noticias_detalhe.cfm?co_seq_not icia=29276. Acesso em: 20 dezembro 2007.

PIRITO, Ma. Considerações sobre o Motorista Idoso. São Paulo:ABRAMET p. 25-27, 1999.

RIBEIRO, Luis Otoni Meireles. TIMM, Maria Isabel e ZARO Milton Antonio. Modificações em jogos digitais e seu uso potencial como tecnologia educacional para o ensino de engenharia. RENOTE - Revista Novas Tecnologias na Educação, CINTED-UFRGS. $\quad$ V. $4 \mathrm{~N}^{\mathrm{O}}$ 1, Julho, 2006. Disponível: www.cinted.ufrgs.br/renote/jul2006/artigosrenote/a36_21203.pdf. Acesso 02 maio 2007.

SNOWDEN, Robert J.; STIMPSON, N.; RUDDLE, A. Roy. Speed perception fogs up as visibility drops. In: NATURE, Vol 392, April, 1998.

Tectran. Apresenta o Simulador SimTraffic. Disponível: http://www.tectran.com.br/noticias/noticias20.php. Acesso em: 29 março 2008.

University of Leeds. Apresenta Driving Simulator. Disponível: http://www.its.leeds.ac.uk/facilities/uolds/cr_idc.php. Acesso em 20 de maio 2007.

VALENTE, José Armando. Por que o computador na Educação. In Computadores e conhecimento: repensando a educação. Campinas: Universidade Estadual de Campinas - UNICAMP, 1993.

RONGHUI, Liu. The Dracula dynamic traffic network microsimulation model. Simulation Approaches in Transportation Analysis: Recent Advanced and Challenges. ed. Kitamura and Kuwahara, Springer, p. 23-56, 2005.

STRADLING, S.G., \& MEADOWS, M.L. Highway Code and aggressive violations in UK drivers. Global Web Conference on Aggressive Driving Issues at, 2000. Disponível em:http://aggressive.drivers.com. Acessado em: 20 maio 2007. 